\title{
Discurso de toma de posesión del Rector Magnífico de la USMA, Ing. Juan Planells
}

\author{
Juan Planells Fernández ${ }^{1}$ \\ ${ }_{1}^{1}$ Rector Magnífico, Universidad Católica Santa María La Antigua (USMA), Apartado Postal 0819-08550, \\ Panamá, República de Panamá.
}

Como seguramente ustedes comprenden, me resulta muy difícil hablarles en una ocasión como esta. Son muchos los sentimientos que me acompañan en este día, y todos se agolpan en mi mente interponiéndose en el camino que le permite a la razón convertirse en palabra.

El verme rodeado del cariño de tantos amigos y amigas con los que hemos compartido por cincuenta años las ilusiones de servir a la Iglesia y al país desde nuestra universidad católica, formando jóvenes bien preparados y comprometidos por construir un Panamá mejor, líderes que orienten a la sociedad en su búsqueda hacia un desarrollo de paz y de bienestar. Ustedes deben ser felices pues han sido fieles al compromiso de servir a los que lo necesitan. Decía José Martí "Ayudar al que lo necesita no solo es parte del deber, sino de la felicidad".

Para los miembros de la Junta de Directores que incluyeron mi nombre en la lista de candidatos, todos con más méritos que yo, vaya mi agradecimiento por su confianza en que puedo ser de utilidad a la USMA en esta etapa de mi vida, (algo sabe el Espíritu Santo sobre mis capacidades que yo desconozco); y al Señor Arzobispo, Gran Canciller de la USMA por haberme seleccionado para ocupar esta honrosa posición, vaya mi compromiso de convertirme en fiel discípulo de su liderazgo y en eficaz misionero de sus enseñanzas.

Y para el Rector Carlos Alberto Voloj mi felicitación por un trabajo bien hecho. Su don de gentes ha marcado una huella imborrable en la comunidad universitaria y su compromiso con el desarrollo de la USMA ha dejado una nutrida hoja de logros que me esforzaré en continuar.

Llegar hasta aquí ha requerido del aliento de muchas personas y por ello quiero que me permitan la licencia de agradecer a mi familia por su acompañamiento y apoyo.

A mi esposa Linda, compañera de 55 años de vida, mejor educadora que yo; a mis cuatro parejas de hijos, todos formados en la USMA más exitosos profesionales que yo, Juan Carlos y Lorena, Maricel 
Invest. pens. crit.

Vol. 3, No. 2, mayo-agosto 2015.

pp. $79-87$

y Fernando, Annette y Toto y Patricia y Rogelio y a mis once nietos que han llenado mi vida de orgullosos momentos: Paola, Juan Carlos, David, Daniel, Ana y Juan Fernando, Beatriz, Irma, Rogelio, Annette Marie, e Isabela. A todos ellos les pido paciencia. Tendrán que esperar cinco años más para recibir la atención que merecen.

Mi vida ha estado llena de satisfacciones. Las mayores están vinculadas a esta institución que a lo largo de su historia me ha dado muestras de un cariño inmerecido. Guardo entre mis mejores recuerdos cuando me nombraron para ocupar la vice rectoría hace casi 50 años, cuando los docentes me eligieron para presidir la Asociación de Profesores de la Universidad hace 25 años, y cuando me confirieron la orden Francisco Javier de Luan Victoria y Castro hace 10 años. Decía Barack Obama, "Gracias por creer hasta el final, a través de cada colina y cada valle. Me habéis llevado sobre vuestros hombros todo el camino y siempre agradeceré todo lo que habéis hecho”.

Me corresponde ahora, de regreso a la casa del saber, reconocer que el verdadero mérito de esta obra está en ustedes que han sabido colocar a la USMA en el destacado sitial en que se encuentra. A pesar de las dificultades y los obstáculos que esta sociedad posmoderna ha puesto en su andar, ustedes han sabido ser fieles hasta el fin en la misión de convertir a nuestros jóvenes en sujetos de su propio desarrollo y el de la sociedad a la que pertenecen.

La celebración de los 50 años de fundación de la USMA es una buena oportunidad para reflexionar como laicos comprometidos con nuestra Iglesia sobre el logro de los objetivos planteados originalmente, cuando se sentaron las bases para crear la universidad católica de Panamá en 1965. Es el momento para plantear, después de medio siglo de experiencia, los pasos que debemos dar en el camino de continuar fortaleciendo su identidad como institución de la Iglesia que busca contribuir con la educación superior en Panamá.

Cada etapa en el desarrollo de la universidad ha dejado un legado de avances en el camino de consolidar la institución que se había proyectado. Primero en la creación del fundamento legal que permitiera la existencia de una universidad particular y católica en Panamá y, en ese sentido, tuvimos que vencer el monopolio estatal y secular que hasta ese momento se ejercía sobre la educación superior. No fue una tarea fácil, pero al lograrlo con el arrojo de sus fundadores, se abría el camino para contar hoy con una variada y valiosa oferta universitaria.

Sobre ese fundamento legal se fue trabajando más tarde en reforzar la justificación académica de la nueva institución. La universidad católica debe ser en primer lugar universidad por excelencia, que se caracterice por la profundidad de su investigación, su docencia y su servicio de extensión a la sociedad a la cual sirve. No se trataba de duplicar las ofertas de formación superior representadas por la universidad oficial, sino de complementarlas con disciplinas diferentes o cultivando diferentemente las mismas disciplinas. Tampoco fue tarea fácil convocar a la intelectualidad panameña para el difícil y duro trabajo en las aulas universitarias. Debíamos competir con dedicaciones de mayor reconocimiento 
económico y social atrayendo profesores y administrativos que aceptaran el reto, casi en condiciones de voluntariado pro bono.

Con base en lo anterior y sobre todo ello, tuvimos que dedicar especial desvelo a demostrar la justificación cristiana de la nueva universidad y a su vinculación con la Iglesia y la jerarquía. ¿Cómo hacer presente la inspiración del Evangelio sobre la comunidad universitaria, y como mostrar los frutos de promover la relación entre fe y vida? En este caso debíamos luchar contra una tradición de valores desvinculados de nuestra actuación como ciudadanos, creando una barrera que separa lo ético de lo cotidiano.

Además, después del crecimiento inicial, se atendió el manejo administrativo y financiero de la institución para darle la requerida sostenibilidad económica. Una compleja estructura universitaria exige la eficiente y eficaz distribución de recursos humanos y materiales que dependen de fuentes de ingresos suficientes y estables. En este caso se hacía necesario plantearse interrogantes como: ¿cuántos estudiantes deben atenderse en condiciones de calidad, cuál es el costo por estudiante o cuál el nivel de remuneración de su personal?. Había que luchar contra la inercia que nos impulsa a un crecimiento en cantidad, sin objetivos claros en sintonía con la calidad de la misión y visión en la USMA. Recuerdo cuando el difunto Menalco Solís, Síndico por excelencia, planteaba que esta universidad debía recibir un balboa de donación por cada balboa aportado por el estudiante. La idea era evitar que el costo de la matrícula excluyera jóvenes con interés y capacidades pero sin recursos. Esto pasó a ser una quimera a medida que su presupuesto crecía, y sigue siendo un objetivo por cumplir.

Durante la etapa más reciente, se han logrado avances en fortalecer una vinculación UniversidadEmpresa que aseguran la pertinencia requerida en la formación de los profesionales demandados por el sector productivo. USMA Empresarial ha sido una iniciativa orientada en esa dirección. Aquí se requiere insistir que se trata de aportar una nueva propuesta de empresa y de empresario, comprometida con la solución de los problemas sociales, y no con la aceptación de sus causas.

No han faltado los problemas que se han tenido que enfrentar con voluntad y decisión corrigiendo rumbos de corrientes que nos tratan de alejar de la meta plantada por sus fundadores, especialmente en esta época caracterizada por un debilitamiento de la espiritualidad, un desmembramiento de la comunidad, y una confusión en cuanto a los caminos para lograr su misión

Un puñado de rectores, religiosos y laicos comprometidos, ha liderado e impulsado cada una de estas etapas con dedicación dignas de observación y agradecimiento. Cada etapa daba muestras del compromiso, y gracias a ello en este momento contamos con una universidad acreditada por la sociedad que ha graduado miles de profesionales idóneos en el ejercicio de sus funciones, y que ha influido con su actuar, sobre la comunidad donde están insertos.

Sin embargo nos queda un largo y difícil camino por recorrer si realmente queremos que la universidad católica de Panamá represente una esperanza frente a la crisis social que vive el país. La inequidad en la distribución de oportunidades, la pobreza, la corrupción, la droga y la violencia, disputan liderazgos 
Invest. pens. crit.

Vol. 3, No. 2, mayo-agosto 2015.

pp. $79-87$

negativos con la satisfacción de notables crecimientos económicos. No podemos sentirnos satisfechos con los antivalores que conspiran cada vez con más fuerza contra aspiraciones de un país mejor.

En esta era de la posmodernidad donde pretendemos juzgar la verdad de una doctrina moral, social, religiosa o científica sobre la base de su utilidad práctica, hemos sido inundados por el egoísmo, la irresponsabilidad, la indiferencia, la intolerancia, la injusticia, el relativismo y la deshonestidad en un pragmatismo social suicida que no resiste la prueba del tiempo y pone en peligro el régimen de libertades y derechos que hoy disfrutamos.

Sucumbimos fácilmente ante la propuesta moderna de un proyecto de vida que solamente busca el placer y la comodidad. Nuestra universidad no escapa a esta influencia negativa en sus estudiantes, docentes y administrativos. Ello hace cada vez más difícil influir en su espiritualidad, su comunidad y su misión, y por ello se requiere de un esfuerzo adicional enfocado en los principios sobre los que se funda la USMA.

Consideramos necesario recordar que la misión de una universidad, y más aún de una universidad católica, no se limita a capacitar para una ocupación especializada de orden científico, profesional o técnico, requerida por el mercado laboral del momento. Esto sin duda es parte importantísima de su misión, pero la tarea de formar buenos profesionales no debe convertirse en objetivo único, descuidando otras metas vinculadas al cultivo de ciencias y promoción del saber, en nuestro caso en diálogo permanente con los valores de la sociedad nacional panameña y latinoamericana, y bajo la inspiración del Evangelio, así como de una formación en la cultura y una orientación en la civilización. Nuestros profesores no son vendedores del conocimiento y nuestros alumnos no son simples clientes

Necesitamos un diálogo interno para revitalizar la justificación cristiana de la universidad, definiendo claramente las formas mediante las cuales lo católico se hace presente en la realidad académica de la USMA, Así debe darse testimonio en el ejercicio de la convivencia dentro de la comunidad que pretendemos construir en la búsqueda de la verdad. También debe manifestarse en la relación entre las diferentes disciplinas alrededor de una Facultad de Teología, (hoy Humanidades), que aspira a mostrar de qué manera nuestras creencias se hacen presentes en el ejercicio de la vida diaria. Hay que sacar a esta Facultad del anonimato y llevarla al protagonismo si pretendemos realmente promover entre nuestros egresados los valores, hoy llamado competencias blandas, auténtica debilidad de nuestra educación del siglo XXI.

Como comunidad cristiana en la búsqueda de la verdad no debe haber espacio dentro de la institución para la desconfianza o el temor que enfrenta, sino para la solidaridad que une, ni lugar para la opacidad en sus acciones que aísla sino para la transparencia que incluye. El docente y el estudiante constituyen los actores de este quehacer universitario en un espacio donde juntos enseñan y aprenden. 


\section{A mis compañeros educadores}

Reconocer la importancia del docente, aumentando el número de aquellos que pueden dedicarse tiempo completo o medio tiempo al trabajo universitario, con mayor estabilidad profesional y mejores incentivos, buscando alternativas de consultorías y promoción de empresas, se convierte para nosotros en un compromiso. Así mismo establecer un sistema preciso de reglamentación, gracias al cual se puede evaluar el modo como los profesores cumplen con los deberes elementales de su cargo en cuanto a asistencia a clases, la rápida corrección de trabajos y exámenes, en cuanto a preparar y cubrir programas adecuados, en cuanto a ofrecer posibilidades bibliográficas de investigación y práctica. Además garantizar su participación activa en las decisiones básicas que afectan a la Universidad. Solo esta participación garantiza que los deberes impuestos al profesorado se vean equilibrados por los derechos correspondientes y se genere por tanto un ambiente de libertad responsable sin la cual la misión del profesor es inconcebible.

\section{A mis estudiantes}

La misma participación debe promoverse en el Grupo Estudiantil. Siguiendo la propuesta del Papa Francisco que les propone "armar líos para sacudir la Iglesia" y en nuestro caso la universidad. Para ello es necesario facilitar su trabajo a la Asociación que los representa, promoviendo la función activa del estudiante en el desarrollo de la docencia a través de cursos y seminarios, períodos de discusión, mesas redondas, etc. Hacer valer su evaluación de los profesores y de los cursos, y recibir al mismo tiempo la evaluación inversa de los profesores.

Debe procurarse ofrecer a los estudiantes oportunidades de trabajo académico administrativo en la Universidad, y trabajos relacionados con sus estudios en empresas y organismos deseosos de colaborar con la USMA. Esto, y el fortalecimiento del sistema de becas debe procurar que el tema económico no se convierta en factor determinante para evitar tener la oportunidad de recibir la formación que la universidad ofrece. Estos por su parte han de colaborar con la misión de recaudación de fondos y la promoción de nuevos estudiantes.

\section{A mis universidades pares}

Así mismo, necesitamos de un diálogo externo con el resto de las universidades, no en el plan de una competencia por espacios de mercado, sino de colaboración y de coordinación que complemente su trabajo mediante nuestro aporte inspirado en el Evangelio. Hay que tener siempre presente que la USMA no es otra universidad privada más en el país sino la universidad que manifiesta en su naturaleza un compromiso con nuestra fe que comienza por eliminar el lucro de entre sus intereses. Admiramos el excelente trabajo que hoy realizan nuestros pares reunidos en el Consejo de Rectores, agrupando universidades oficiales y particulares que realmente han avanzado hacia la luz. Su decidido compromiso con la calidad de la educación superior los ha llevado a proponer una legislación que crea el Sistema Nacional de Evaluación Superior de las Universidades con importantes logros como la acreditación. 
Invest. pens. crit.

Vol. 3, No. 2, mayo-agosto 2015.

pp. $79-87$

\section{A mi Iglesia}

Tratándose de una universidad moderna debe buscar formas de relación con la jerarquía en sintonía con las orientaciones de Vaticano II, Puebla y Aparecida que nos hablan de una apertura al diálogo con la cultura profana y abierta para servir al mundo, que logre frutos de evangelización mediante el testimonio de una vida auténtica. Esto, que supone un respeto por la justa autonomía de la realidad terrena, en ningún modo puede interpretarse como una ausencia en la institución de los valores que nos inspiran y de sus fuentes evangélicas.

La presencia de la Capellanía en la vida universitaria debe reforzarse encargándose de promover, entre todas las personas vinculadas a la Universidad, el anhelo de mejorar su vida cristiana en consonancia con la preparación científica y profesional que se imparte en la universidad, y facilitar los medios necesarios para ello; y con ese objetivo habrá que dotarla de los instrumentos que faciliten su labor dentro de la universidad.

El vínculo con el seminario que forma sacerdotes debe aprovecharse en todo su valor, no solamente en cuanto al aporte académico de su presencia sino a la contribución espiritual de un convivio que enriquece, por lo que estrechar relaciones entre ambos instituciones será un compromiso renovado. La universidad se inspira en los valores de la Revelación Cristiana y por ello, lo católico en la USMA deber ser algo más que una capilla vacía y debe convertirse en forma de vida. Esto también supone su apertura ecuménica hacia todas las expresiones de fe religiosa y por una respetuosa atención hacia las posturas divergentes que los hombres de buena fe adoptan en cuanto a los valores religiosos.

La universidad abierta del posconcilio supone condiciones de seriedad académica, honradez científica, apertura al diálogo y libertad académica que no es frecuente encontrar en nuestra cultura universitaria. Su acción ha de estar basada sobre la visión de sus fundadores en cuanto a su espiritualidad, su visión de comunidad entre los miembros, y su misión evangelizadora.

El diálogo externo también debe incluir a la comunidad católica que ha permanecido fuera de los ámbitos de la universidad. La USMA debe ser el imán que atraiga movimientos de Iglesia, grupos de base, intelectuales y educadores católicos donde se planteen los problemas de nuestro tiempo y se ofrezca orientación bajo la metodología de ver, juzgar y actuar sugerido por la encíclica Madre y Maestra. Según la V Conferencia General del Episcopado Latinoamericano y del Caribe reunida en Aparecida "Las actividades de una universidad católica deberán vincularse y armonizarse con la misión evangelizadora de la Iglesia".

\section{A nuestra sociedad}

La USMA también se inspira en los valores de la sociedad nacional panameña y latinoamericana. Eso exige que la universidad enjuicie libremente, formule orientaciones intelectuales y proponga posibles modelos de solución a los problemas fundamentales el hombre y de la sociedad a la que sirve. 
No parece en sintonía con nuestros propósitos competir por un aumento en la matrícula sobre la base de reducir nuestra oferta en calidad y tiempos. Optamos por una población estudiantil que nos permita atender sus necesidades de una formación superior con un profesorado que no ceda en sus requisitos para complacer crecimientos sin control; por lo que insistiremos en rigurosos exámenes de admisión fundados en actitudes y aptitudes que garanticen resultados porque sembramos en tierra fértil. Tenemos muchos profesionales en Panamá, pero nos faltan aquellos bien preparados en los que podamos confiar nuestro crecimiento económico y desarrollo social por sus conocimientos y sus valores.

Otro tema que queremos subrayar es la importancia de una formación en competencias genéricas llamadas hábitos o competencias blandas, sobre la base de una Facultad de Humanidades fuerte, en diálogo con otras ciencias. Después de todo, la mayor debilidad de nuestra sociedad del siglo XXI está en los valores y no solamente en el desarrollo de la ciencia y la tecnología. La ética será un eje que imprima un sello en el profesional de la USMA y su inspiración cristiana será una garantía.

\section{Nuestra vocación de servicio}

El servicio social como trabajo de extensión universitaria debe fortalecerse y sobresalir como un testimonio de compromiso del egresado con la acción, convirtiéndose en el sello que distinga a nuestros profesionales. Los marginados del progreso en Panamá necesitan con urgencia de la presencia de estos jóvenes en el campo y la ciudad, ofreciendo ayuda social y oportunidades de desarrollo para romper el círculo de pobreza que hoy los atrapa. Nos proponemos fundar en la USMA un Centro de Equidad que vea, juzgue y actúe frente a la legión de panameños que esperan un espacio de participación. Así mismo nos comprometemos a trabajar muy de cerca con el Centro Nacional de Productividad que muestra una larga historia de éxitos en su misión de hacer al país más competitivo, para mantener los niveles de crecimiento económico de los que hoy disfrutamos. Ya colaboramos activamente en la conformación de la mesa de Inclusión Social dentro del 9no. Foro Nacional de Competitividad celebrado recientemente, consciente que para competir mejor tenemos que incluir a todos y todas en el compromiso de crear riqueza.

Esta identidad como universidad católica de Panamá debe estar claramente definida en la impronta que lleven nuestros estudiantes, en el compromiso de nuestros docentes y administrativos, y en el mensaje que trasmitimos a la sociedad a través de los medios de comunicación y de las redes sociales. Nuestro mercadeo no es de productos, sino de promoción de oportunidades para atraer a los que quieran acompañarnos en esta aventura por una mejor formación y una mayor participación en el mejoramiento de la sociedad panameña.

\section{Nuestra misión}

Como institución de educación superior en Panamá, la USMA se integra al sistema panameño y latinoamericano con sentido de iniciativa y de complementariedad. Frente a un mundo cambiante debe 
Invest. pens. crit.

Vol. 3, No. 2, mayo-agosto 2015.

pp. $79-87$

ser flexible en su ordenamiento normativo para responder a las necesidades y aspiraciones de la sociedad a la que pretende servir. No se trata de someternos a las exigencias de un mercado sin objetivos claros, es orientarlo para que sepa exigir lo que el país necesita y lo pueda evaluar.

Como centro vital de cultura, hemos de ser eje donde converjan y se conjuguen los valores fundamentales de un renovado y pleno humanismo, con un enfoque a la vez crítico y creador, fomentando la identidad nacional propia de Panamá y América Latina. Pretendemos generar este examen para el diagnóstico y la prospección en combinación con Centros de Pensamiento como la Fundación para el Desarrollo Económico y Social de Panamá FUDESPA, que aunque joven ya puede exhibir una fructífera historia de propuestas en políticas públicas, con el Movimiento de Profesionales Católicos que ha presentado una visión de El Panamá que Queremos, con el movimiento Unidos por la Educación, que asume el compromiso de colaborar con todos los actores sociales para mejorar las condiciones del sistema educativo y otras como la Fundación del Trabajo que agrupa a los principales líderes del sector laboral y empresarial panameño como muestra de nuestra capacidad de desarrollar sinergias para enfrentar la grave problemática social. La USMA se propone como plataforma para debatir importantes temas como el liderazgo compartido entre hombre y mujer, la protección al medio ambiente, el diálogo con los pueblos originarios, el trabajo infantil, que forman parte de la agenda nacional y global.

Como se dedica al cultivo de las ciencias y a la promoción del saber, la universidad debe hacerlo en base a la investigación propedéutica y creadora, según una exigente metodología, sentido de coordinación interdisciplinaria y trabajo en equipo. La investigación rigorosa, edición de libros, publicaciones en revistas indexadas, pasan a ser un objetivo que comparte méritos con la docencia. Esta labor debe estar directamente vinculada a la docencia y debe servir tanto para la iniciación de los estudiantes al proceso de conocimiento como en cuanto a la participación de los profesores. Por ello fortaleceremos los vínculos con la Secretaría Nacional de Ciencia y Tecnología, Ciudad del Saber y con otras universidades con las que promoveremos alianzas para la investigación interdisciplinaria compartida.

Como se dedica también a capacitar para una ocupación especializada de orden científico profesional o técnico el trabajo universitario exige que se tomen en cuenta la vocación personal del estudiante y las necesidades comunitarias de la sociedad en la que ha de rendir sus servicios. Un contacto vivo y continuo con los líderes del sector productivo muchos de los cuales hoy nos acompañan: el Consejo Nacional de la Empresa Privada, APEDE y sus miembros, gremios que representan la actividad económica que nos sostiene, compañeros de tanta frustración ante la necesidad de contar con colaboradores bien formados, nos permitirá conocer las áreas que requieren apoyo y detectar las competencias laborales que en cada una de ellas son necesarias. Cada carrera en la USMA contará con un listado de las competencias que persigue, y el diseño de indicadores publicados que nos permitan evaluar su cumplimiento y corregir sus distorsiones. En esto contaremos también con la presencia del sector trabajador que cuenta con la experiencia del centro de trabajo a través de sus organizaciones sindicales. 
Y como se dedica a una formación en la cultura y a una orientación en la civilización ha de adoptar formas de convivencia imbuidas de un espíritu de servicio a la dignidad de la persona dentro del contexto del bien común de la sociedad. Abriremos un espacio para representantes de la sociedad civil organizada como Alianza Ciudadana Pro justicia, la Comisión de Justicia y Paz, el Foro mujer y desarrollo, Transparencia Internacional y otras. El Documento sobre Educación, en la segunda conferencia general del episcopado latinoamericano reunido en Medellín, nos dice: "La Universidad debe estar integrada en la vida nacional y responder con espíritu creador y valentía a las exigencias del propio país”. Eso espera la sociedad de una universidad que debe ser conciencia crítica de la Nación.

A todos los que hoy me acompañan en este momento muy especial, les reitero mi disposición a servir, asumiendo este compromiso con humildad y pido sus oraciones para poder cumplir con mi deber en esta nueva prueba que me ha tocado enfrentar. Fácil reto que desempeñar si ustedes me acompañan.

Muchas gracias. 